\title{
BMJ Open Adherence to oral anticoagulants among patients with atrial fibrillation: a systematic review and meta-analysis of observational studies
}

\author{
Shahrzad Salmasi (D) , , ${ }^{1,2}$ Peter S Loewen, ${ }^{1,2}$ Rachel Tandun, ${ }^{2}$ Jason G Andrade,,${ }^{3,4}$ \\ Mary A De Vera ${ }^{1,2}$
}

To cite: Salmasi S, Loewen PS, Tandun R, et al. Adherence to oral anticoagulants among patients with atrial fibrillation: a systematic review and meta-analysis of observational studies. BMJ Open 2020;10:e034778. doi:10.1136/ bmjopen-2019-034778

- Prepublication history and additional material for this paper are available online. To view these files, please visit the journal online (http://dx.doi org/10.1136/bmjopen-2019034778).

Received 05 0ctober 2019 Revised 06 March 2020 Accepted 26 March 2020

\section{Check for updates}

(c) Author(s) (or their employer(s)) 2020. Re-use permitted under CC BY-NC. No commercial re-use. See rights and permissions. Published by BMJ.

${ }^{1}$ The University of British Columbia, Collaboration for Outcomes Research and Evaluation (CORE), Vancouver, British Columbia, Canada

${ }^{2}$ Faculty of Pharmaceutical Sciences, University of British Columbia, Vancouver, British

Columbia, Canada

${ }^{3}$ Faculty of Medicine, University of British Columbia, Vancouver, British Columbia, Canada ${ }^{4}$ Department of Medicine, Montreal Heart Institute, Université de Montréal, Montreal, Quebec, Canada

Correspondence to Dr Shahrzad Salmasi; shahrzad.salmasi@ubc.ca

\section{ABSTRACT}

Introduction Medications cannot exert their effect if not taken as prescribed by patients. Our objective was to summarise the observational evidence on adherence to oral anticoagulants (OACs) among patients with atrial fibrillation (AF).

Methods In March 2019, we systematically searched PubMed/Medline, Embase, CINAHL and PsycINF0 (from inception) for observational studies measuring adherence, its determinants and impacts in patients with AF. Mean adherence measures and corresponding proportions of adherent patients were pooled using random effects models. Factors shown to be independently associated with adherence were extracted as well as the clinical and economic outcomes of adherence.

Results We included 30 studies. Pooled mean adherence scores of over half a million patients with AF 6 months and 1 year after therapy initiation were 77 (95\% Cl: 74-79) and 74 (68-79) out of 100 , respectively. Drug-specific pooled mean adherence score at 6 months and 1 year were as follows: rivaroxaban: 78 (73-84) and 77 (69-86); apixaban: 77 (75-79) and 82 (74-89); dabigatran: 74 (69$79)$ and 75 (68-82), respectively. There was inadequate information on warfarin for inclusion in meta-analysis. Factors associated with increased adherence included: older age, higher stroke risk, once-daily regimen, history of hypertension, diabetes or stroke, concomitant cardiovascular medications, living in rural areas and being an experienced OAC user. Non-adherent patients were more likely to experience stroke and death, and incurred higher medical costs compared with patients with poor adherence.

Conclusions Our findings show that up to $30 \%$ of patients with $\mathrm{AF}$ are non-adherent, suggesting an important therapeutic challenge in this patient population.

\section{INTRODUCTION}

Atrial fibrillation (AF) - the most common chronic arrhythmia-is an epidemic affecting more than 33 million people worldwide. ${ }^{1} \mathrm{AF}$ increases stroke risk by up to fivefold and is responsible for a third of strokes in people over $60 .^{2-5}$ Strokes secondary to AF are far more debilitating and carry three times
Strengths and limitations of this study

- This is a timely systematic review that synthesises the evidence on extent of poor adherence to oral anticoagulants, its determinants and clinical and economic outcomes, among patients with atrial fibrillation.

- We focused on observational studies (retrospective and prospective) to synthesise the evidence on patients' real-world medication taking behaviour.

- We considered all oral anticoagulants, including the newer drugs (apixaban, rivaroxaban, dabigatran and edoxaban) and aimed to generate pooled adherence at the individual drug level.

- Drug utilisation consists of three interconnected but distinct phases (initiation, implementation and discontinuation) and the focus of this study was confined to the implementation phase.

the risk of death than strokes due to other causes. ${ }^{6-8}$

Oral anticoagulants (OACs), which include vitamin $\mathrm{K}$ antagonists (VKA) and direct oral anticoagulants (DOACs), are the only effective agents thus far in preventing stroke in patient with $\mathrm{AF}$, showing approximately $66 \%$ relative risk reduction in clinical trials. ${ }^{9-13}$ When used outside the controlled environment of clinical trials, however, the effectiveness of these drugs is impacted by patients' adherence. ${ }^{14}{ }^{15}$ The clinical consequences of non-adherence can potentially be more significant for DOACs, given their short half-lives. ${ }^{14-18}$

Studies have previously attempted to summarise the medication taking behaviour of patients with AF. These reviews, however, focus on discontinuation of therapy (not implementation or execution of dosing), or when looking at implementation, only focus on DOACs, summarise evidence from randomised controlled trials (which do not 
reflect the day to day behaviours of patients) and provide a narrative summary of results with no meta-analysis. ${ }^{19-21}$ Further, no studies have summarised the evidence on determinants of adherence in this patient population and the association between adherence and outcomes (clinical or economical). The objective of this systematic review and meta-analysis was to summarise the evidence from observational studies on the extent, determinants and impacts of adherence to all OACs among patients with AF.

\section{METHODS}

We conducted a systematic review and meta-analysis following the Preferred Reporting Items for Systematic Reviews and Meta-Analyses and the Meta-analysis Of Observational Studies in Epidemiology guidelines (online supplementary file 1 ).$^{22} 23$

\section{Search strategy}

In March 2019, we systematically searched PubMed/ Medline, Embase, CINAHL and PsycINFO (from inception) using the relevant keywords and $\mathrm{MeSH}$ terms (online supplementary file 2). The search strategy was designed with the help of a medical librarian and aimed to identify peer-reviewed published manuscripts that reported on extent, determinants and impacts of non-adherence to any OAC. A manual search was also performed on Google Scholar and the bibliography of included studies.

\section{Inclusion criteria and study selection}

Studies were included if they used a prospective or retrospective observational study design, and quantitatively measured secondary adherence (also known as the 'implementation' phase), which looks at medication dose omissions, additions or delays and does not involve those who did not initiate their therapy ${ }^{15}$ Studies published in English, French, Spanish, Persian, Finnish, Cantonese or Korean were included. ${ }^{24}$ No limitations were imposed on setting, country, publication date or quality.

While we were primarily interested in OAC adherence in patients with non-valvular AF, we included studies that did not specifically restrict inclusion to this population, with notation in quality assessment. Studies of self-reported adherence were excluded (including those using validated scales such as Morisky Medication Adherence Scale ${ }^{\odot}$ ) as they are prone to overestimation of adherence (social desirability bias) ${ }^{24}$ Cross-sectional and interventional studies, editorials, conference proceedings and studies that evaluated or validated adherence measurement methods were also excluded.

Two authors independently screened titles and abstracts of the retrieved studies followed by full text review of candidate studies. Disagreements about inclusion were resolved by discussion with a third author.

\section{Data extraction and synthesis}

The primary adherence measure extracted was the mean and SD of patients' adherence over 6 months or 12 months post index date (after therapy initiation). The secondary adherence measure was proportions of adherent patients, that is proportion of patients reported in each study to have mean adherence score more than 80 (this could be $>$ or $\geq$ depending on how the study defined 'adherent'). The $80 \%$ adherence is the conventional threshold for 'good adherence'. ${ }^{25}{ }^{26}$ Six or twelve months were chosen as these were the most common follow-up times. If a study had variable follow-up time (eg, from initiation to permanent discontinuation or death), the median follow-up time was used. For studies that reported the proportion of non-adherent participants, data were transformed to proportion adherent to allow pooling. When both unadjusted and adjusted outcomes were reported, we extracted and analysed the adjusted results. When unmatched and propensity score matched results were reported, we extracted the matched results as they were expected to be more accurate estimates. When a study reported adherence to both index OAC and current OAC (allowing for switching), adherence to index OAC was analysed to minimise heterogeneity since studies defined switching differently. Adherence results with switching allowed were still reported.

We extracted information on the determinants or factors shown in the included studies to be independently associated with adherence in multivariable regression analyses. We classified the identified determinants under the WHO's five dimensions of medication adherence to identify areas in need of more research. ${ }^{27}$ Finally, we extracted information on the clinical and economic consequences of poor adherence.

\section{Data analysis}

Meta-analyses were carried out using DerSimonian and Laird random-effects models to determine the pooled mean adherence and the corresponding pooled proportion of adherent patients over 6 months and 1 year of observation. If a study reported adherence scores for multiple cohorts, all were included in the meta-analysis (multiple entries per study). In anticipation of heterogeneity, subgroup analysis was performed for each adherence measure, by presence of potential conflict of interest and study quality. Additional meta-analyses were also performed focusing only on studies that reported comparative adherence between different OACs in the same cohort, to calculate the pooled OR of adherence for each comparison.

$\mathrm{I}^{2}$ statistics was used to quantify heterogeneity between studies. ${ }^{28}$ Leave-one-out analysis was also performed for outliers to explore and potentially reduce heterogeneity. ${ }^{29}$ Forest plots and funnel plots were constructed using OpenMeta-Analyst (Microsoft Corporation, Redmond, Washington, USA) or RevMan5 (V. 5.3, Copenhagen, Denmark) software to illustrate the results and assess publication bias using funnel plots where relevant, that 
is, where studies reported measures of association (eg, OR). ${ }^{30} 31$ Clinical and economic impacts of poor adherence were summarised narratively as meta-analysis was not possible.

\section{Quality assessment}

We critically appraised the quality of adherence measurement in the included studies by adapting a condensed version of the checklist designed by the International Society of Pharmaco-economics and Outcomes Research (ISPOR) Group, designed specifically for medication adherence studies, to establish standards for data sources, operational definitions, measurement of medication adherence and reporting of results, previously used in a systematic reviews of adherence to gout medication. ${ }^{32}$ We also critically appraised individual study reporting quality using Strengthening the Reporting of Observational Studies in Epidemiology. ${ }^{33}$ Studies received a point for each checklist item they met and a 0 score if not met. A quality score was computed for each study (number of items satisfactorily met/the total number of applicable items) and reported as a percentage. Items deemed not applicable were excluded from the denominator of the study's score. Studies were categorised as low, moderate or high quality if they scored $\leq 50 \%, 51 \%-80 \%$ or $>80 \%$, respectively (arbitrary thresholds defined by authors).

Following Cochrane's commercial sponsorship policy as a guide, potential conflicts of interest were deemed present if any of the following were met: (1) provision of study funding by the for-profit manufacturer or marketer of any of the OACs included in the corresponding study or (2) disclosure of potential conflict of interest with a for-profit manufacturer or marketer of any of the OACs included in the corresponding study. ${ }^{34}$

\section{Patient and public involvement}

Patients or the public were not involved in the design, or conduct, or reporting, or dissemination of our research.

\section{RESULTS}

Initial search led to 1122 studies, all of which were in English (figure 1). A total of 30 studies were included in this systematic review ${ }^{35-64}$ involving 593683 participants (DOAC: 437 610, VKA: 156 073). Most studies were published after 2015 ( $n=22,73 \%$ of total included), conducted in North America $(\mathrm{n}=19,63 \%)$ and retrospective $(n=29,97 \%)$ (table 1$)$. Adherence measurement was assessed to be of high quality in $59 \%$ of the included studies and moderate in $38 \%$, according to the ISPOR checklist (online supplementary file 3). The most frequently reported adherence measures were proportion days covered (PDC) ( $n=21,70 \%$ of the included studies) and medication possession ratio (MPR) $(n=9,20 \%)$ over 6 months or 1 year post index date (table 2 ). The majority of the included studies focused on adherence to DOACs with only four observational studies measuring and reporting adherence to warfarin. There were no data on adherence to edoxaban, betrixaban, phenprocoumon, acenocoumarol or fluindione.

\section{Adherence}

The range of reported adherence results was quite wide. Reported mean adherence ranged between 67 (out of 100$)^{586164}$ and $86^{55}$ over 6 months and $57^{58}$ and $86^{41}$ over 1 year post index date, with corresponding reported

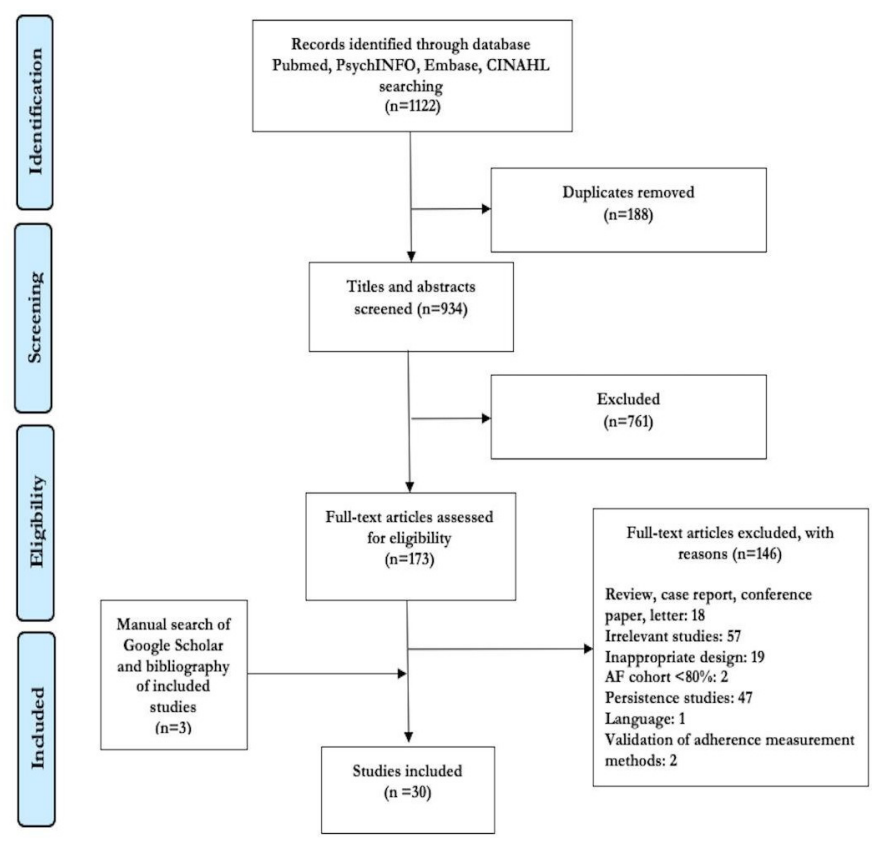

Figure 1 Preferred Reporting Items for Systematic reviews and Meta-Analyses flow diagram that details the number of studies identified by our search strategy screened and included in the final analysis. 


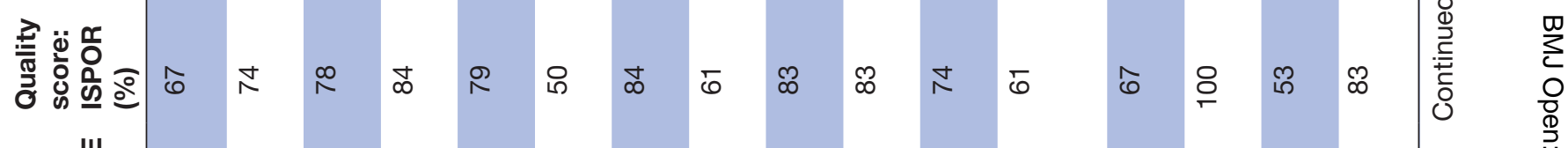

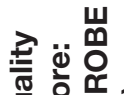

亭砤

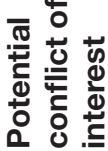

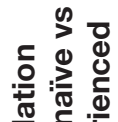

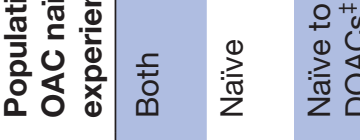

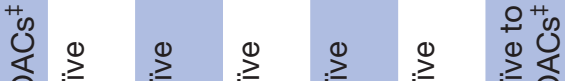

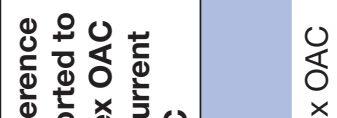

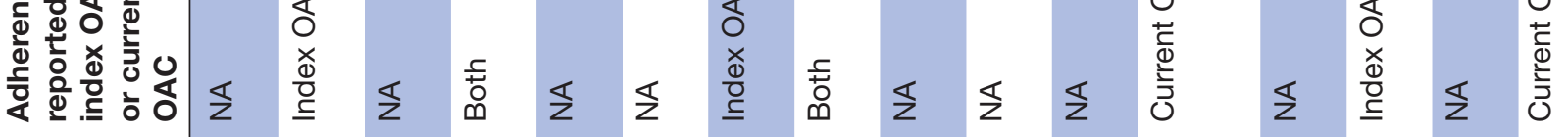

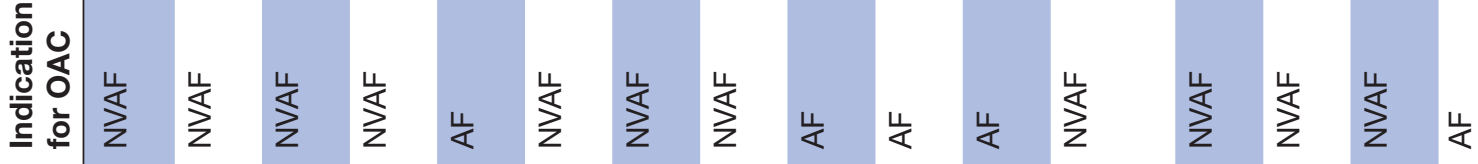

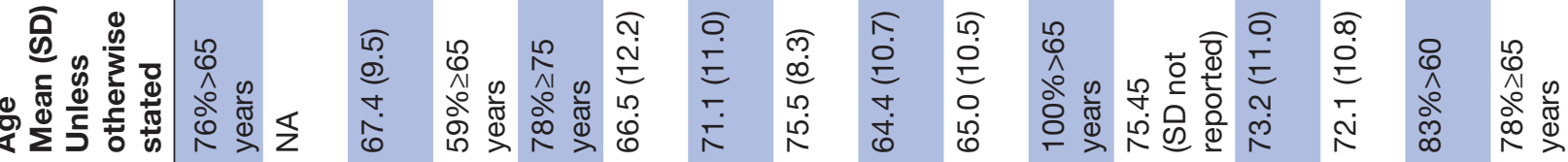

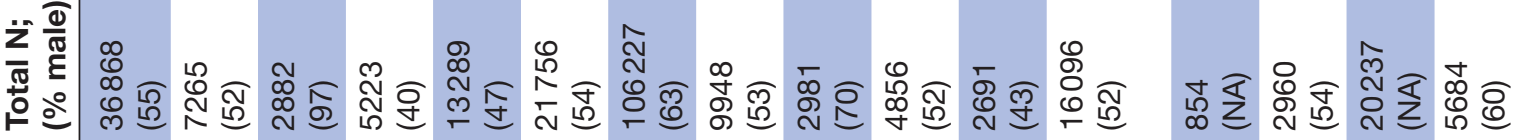

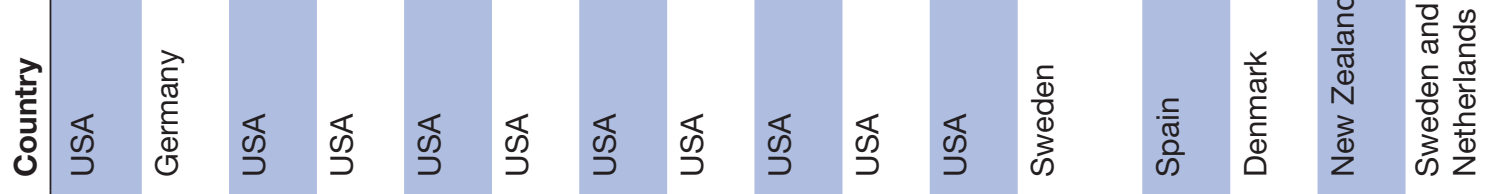

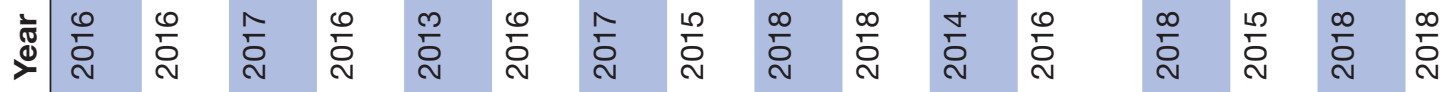
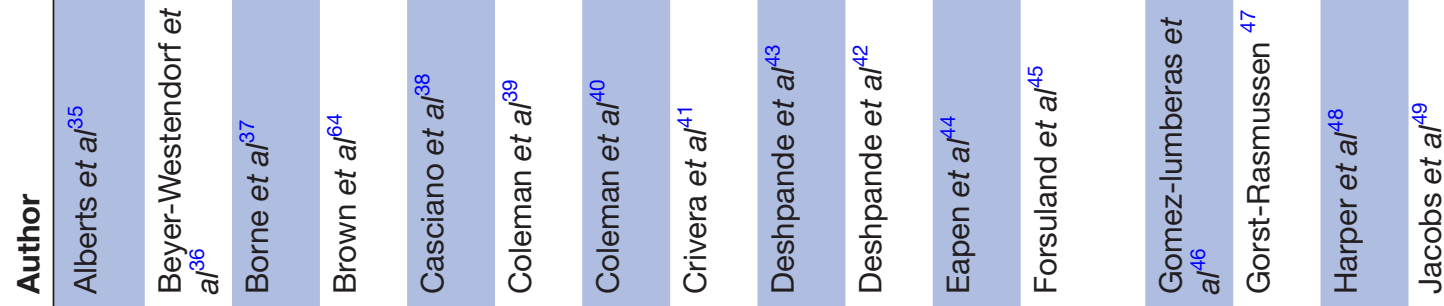


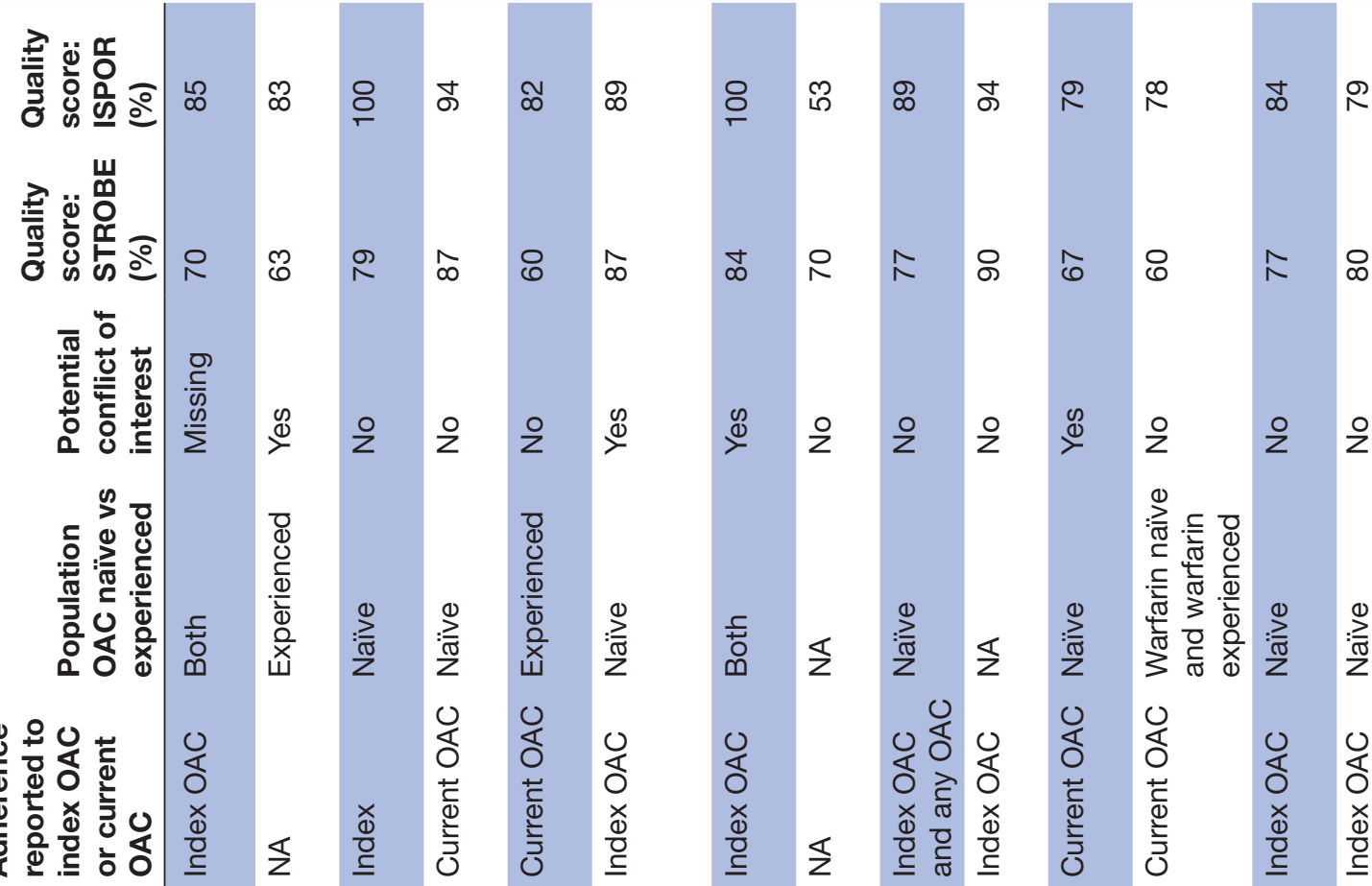

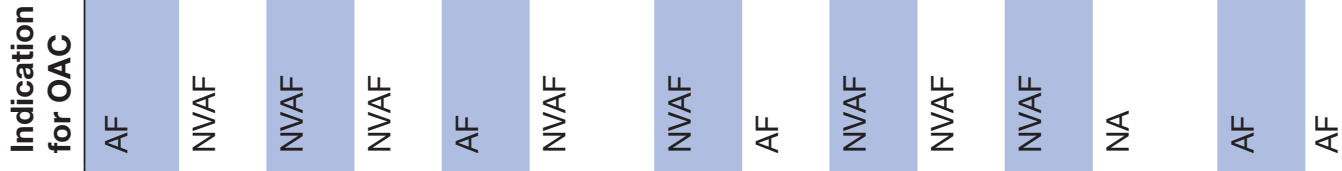

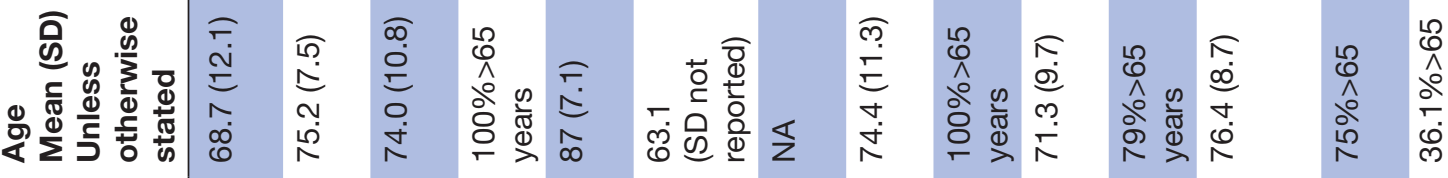

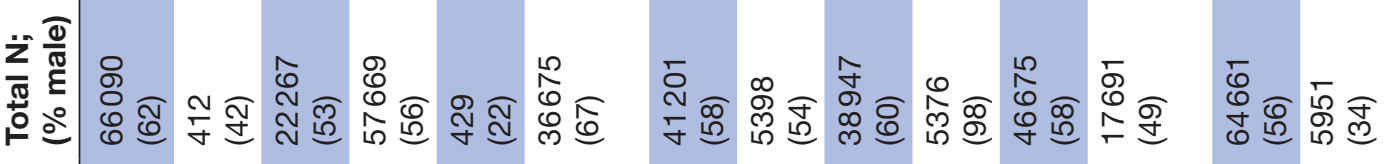

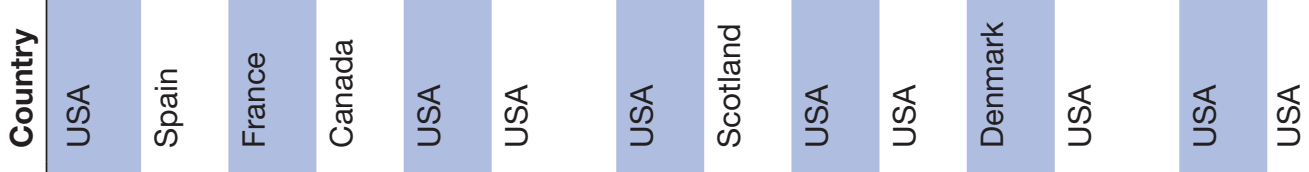

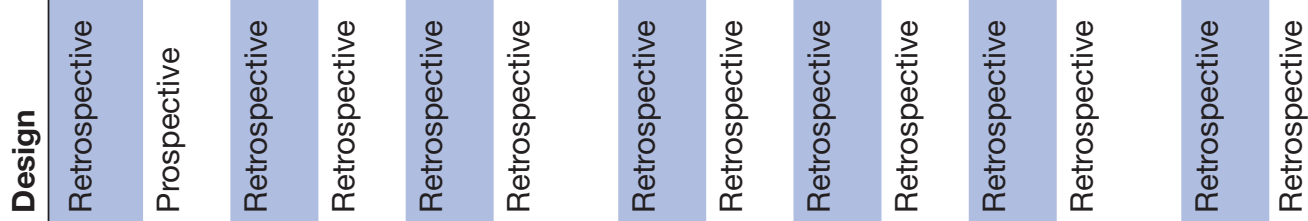

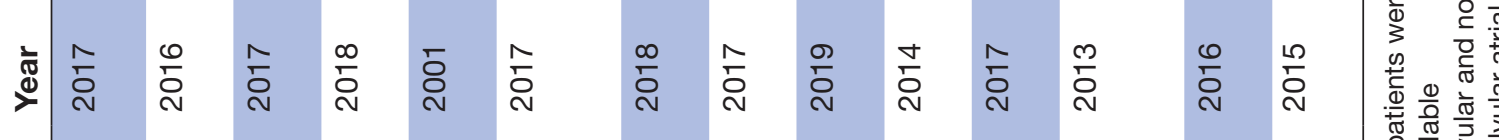


Table 2 Measurement and reporting of adherence to OACs by included studies

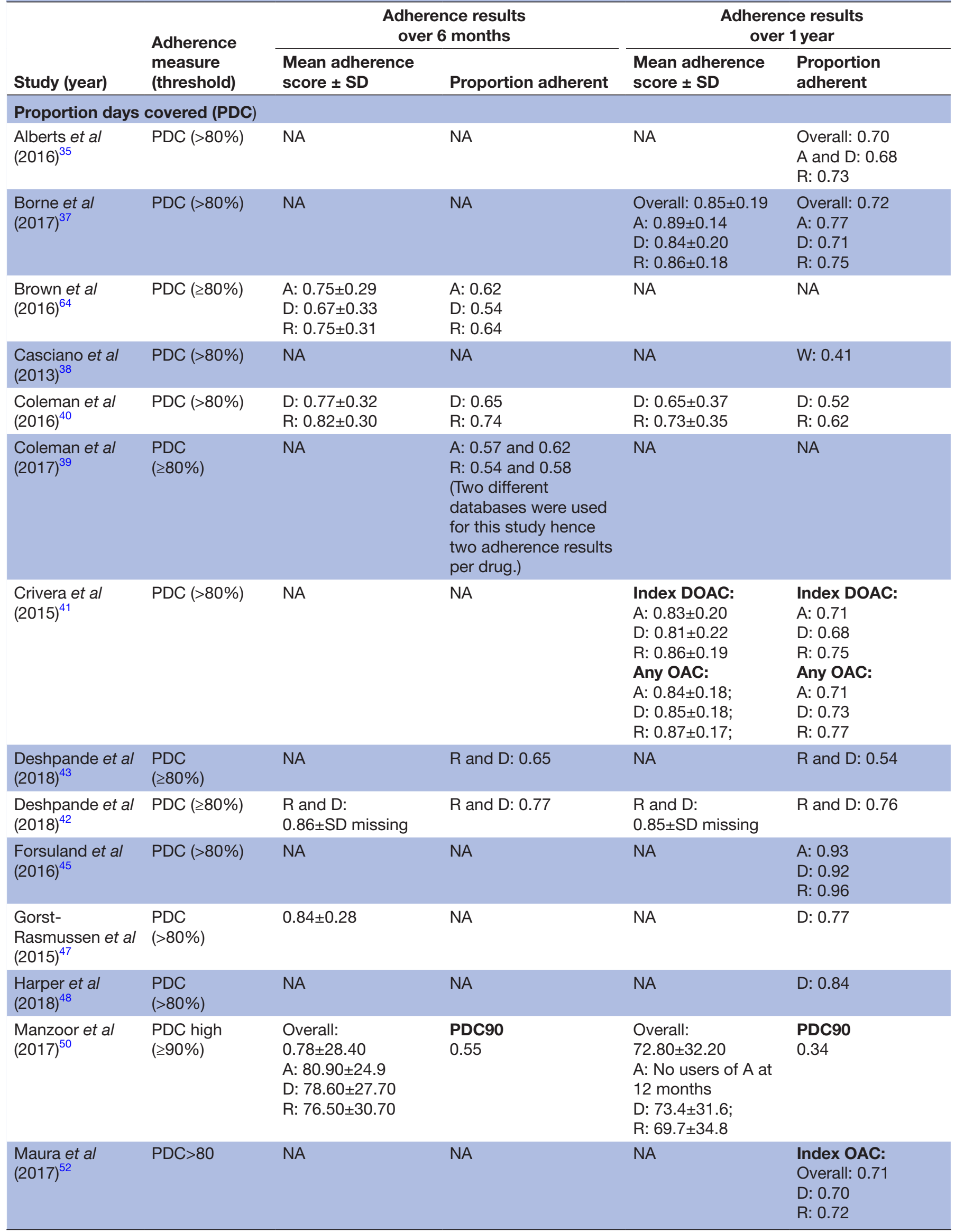


Table 2 Continued

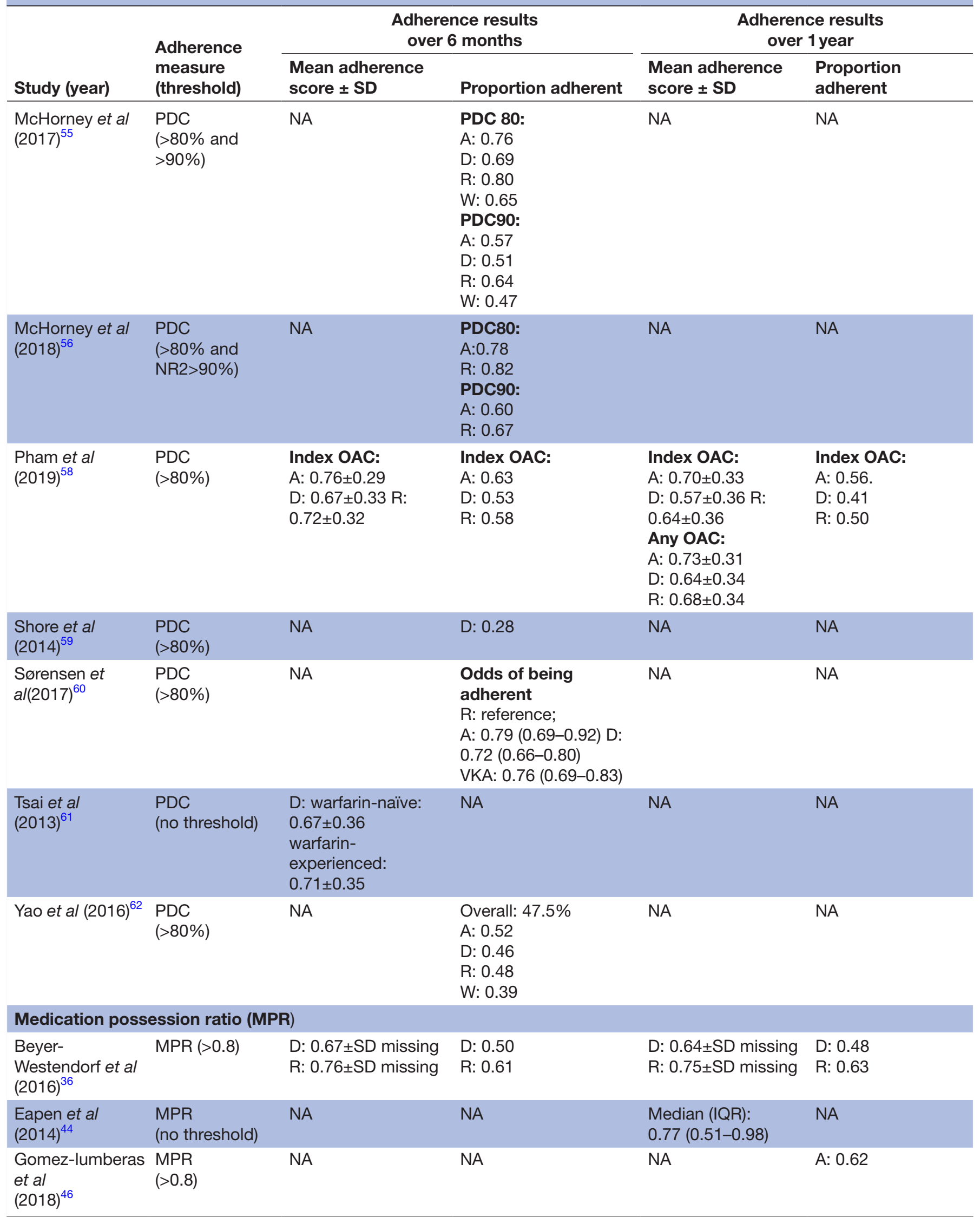

Continued 


\begin{tabular}{|c|c|c|c|c|c|}
\hline \multirow[b]{2}{*}{ Study (year) } & \multirow{2}{*}{$\begin{array}{l}\text { Adherence } \\
\text { measure } \\
\text { (threshold) }\end{array}$} & \multicolumn{2}{|c|}{$\begin{array}{l}\text { Adherence results } \\
\text { over } 6 \text { months }\end{array}$} & \multicolumn{2}{|c|}{$\begin{array}{c}\text { Adherence results } \\
\text { over } 1 \text { year }\end{array}$} \\
\hline & & $\begin{array}{l}\text { Mean adherence } \\
\text { score } \pm \text { SD }\end{array}$ & Proportion adherent & $\begin{array}{l}\text { Mean adherence } \\
\text { score } \pm \text { SD }\end{array}$ & $\begin{array}{l}\text { Proportion } \\
\text { adherent }\end{array}$ \\
\hline $\begin{array}{l}\text { Jacobs et al } \\
(2018)^{49}\end{array}$ & $\begin{array}{l}\text { MPR } \\
(\geq 0.8)\end{array}$ & NA & NA & NA & $\begin{array}{l}\text { Sweden: } 0.95 \\
\text { Netherlands: } 0.93\end{array}$ \\
\hline $\begin{array}{l}\text { McHorney et } \\
a /(2017)^{55}\end{array}$ & $\begin{array}{l}\text { MPR } \\
(>0.8)\end{array}$ & NA & NA & $\begin{array}{l}\text { A: } 0.85 \pm 0.2 \\
\text { D: } 0.81 \pm 0.2 \\
\text { R: } 0.86 \pm 0.2 \\
\text { W: } 0.80 \pm 0.2\end{array}$ & $\begin{array}{l}\text { A: } 0.76 \\
\text { D: } 0.66 \\
\text { R: } 0.78 \\
\text { W: } 0.59\end{array}$ \\
\hline $\begin{array}{l}\text { Zhou et al } \\
(2015)^{63}\end{array}$ & $\begin{array}{l}\text { MPR } \\
(>0.8)\end{array}$ & D: $0.73 \pm 0.30$ & D: 0.59 & D: $0.65 \pm 0.35$ & D: 0.51 \\
\hline $\begin{array}{l}\text { Mueller et al } \\
(2017)^{57}\end{array}$ & MPR $>80^{*}$ & NA & NA & NA & $\begin{array}{l}\text { DOACs: } 0.82 \\
\text { A: } 0.88 \\
\text { D: } 0.65 \\
\text { R: } 0.83\end{array}$ \\
\hline $\begin{array}{l}\text { McAlister et al } \\
(2018)^{53}\end{array}$ & $\begin{array}{l}\text { TTR >65\% } \\
\text { (INR2-3) }\end{array}$ & NA & $\begin{array}{l}\text { W: Per cent patients } \\
\text { with time in therapeutic } \\
\text { range: } 4.11 \%\end{array}$ & NA & NA \\
\hline
\end{tabular}

Drug specific proportion of adherent patients was calculated as the per cent of total number of patients taking the respective drug in the study and not the total number of patients in the study.

${ }^{*}$ Referred to as medication refill adherence in the study (total days' supply/total days in study) $\times 100$.

aHR, adjusted HR; CP, compliance percentage; DOAC, direct oral anticoagulant; MPR, medication possession ratio; NA, not available/not applicable; OAC, oral anticoagulant; PDC, proportions days covered; TTR, time in therapeutic range; VKA, vitamin $\mathrm{K}$ antagonist.

proportion of adherent patients ranging between $47 \%{ }^{59}$ and $82 \%^{56}$ over 6 months and $41 \%^{58}$ and $95 \%{ }^{45}$ over 1 year. A wide range of adherence results were observed even at the individual OAC level (table 2).

Pooled mean adherence scores over 6 month and 1 year post medication initiation were 77 (95\% CI: 74-79) and 74 (68-79), with the corresponding pooled proportion of adherent patients as $63 \%(58 \%-68 \%)$ and $70 \%$ (65\%-76\%), respectively. Adherence was similar between DOACs, although adherence to apixaban and rivaroxaban was slightly higher than dabigatran (table 3). No meta-analysis could be conducted for mean adherence to warfarin since this was not reported by the included studies. Pooled estimates of proportion of adherent patients for warfarin resulted from meta-analysis of two studies only (as illustrated in tables 2 and 3). Due to the limited data in warfarin, no drug class comparison could be made. Figure 2 illustrates the forest plots for patients' mean adherence score over 6 months and 1 year. The remaining forests plots, including forest plots of proportion adherent, adherence to individual OACs, subgroup analyses (by adherence measure (PDC and MPR), study quality and potential for conflict of interest) can be found in online supplementary file 4 .
Between-study variance (represented as $\mathrm{I}^{2}$ ) was high and not reduced by the leave-one out analysis or subgroup analysis. Exclusion of studies with potential conflicts of interest led to lower adherence scores for all OACs but did not change the rank-order of OACs (adherence to dabigatran remained lower than the others). Excluding studies of low and moderate quality or stratifying the analysis by adherence measure (PDC vs MPR) or country (USA vs others) had only minor impacts on pooled adherence results and the detected heterogeneity (online supplementary file 4).

Studies comparing adherence between different OACs in the same cohort

Nineteen studies reported comparative adherence between different OACs in the same cohort (table 4). ${ }^{35-3739-4549505255-586062}$ Odds of being adherent was significantly higher for apixaban compared with dabigatran over both 6 months (OR:1.24, 95\% CI: $1.07-$ 1.45) and 1 year post index date (OR:1.76, 95\% CI: $1.35-$ 2.29). Odds of adherence was significantly higher for rivaroxaban compared with dabigatran over 6 months (OR:1.39, 95\% CI: 1.15-1.67), but not 1 year (OR:1.17, 95\% CI: $0.38-3.60)$. Odds of adherence did not differ 
Table 3 Pooled adherence results

\begin{tabular}{|c|c|c|c|c|}
\hline & \multicolumn{2}{|c|}{ Adherence over 6 months post index date } & \multicolumn{2}{|c|}{ Adherence over 1 year post index date } \\
\hline & $\begin{array}{l}\text { Mean } \\
(95 \% \mathrm{Cl})\end{array}$ & $\begin{array}{l}\text { Proportion adherent } \\
(95 \% \mathrm{Cl})\end{array}$ & $\begin{array}{l}\text { Mean } \\
(95 \% \mathrm{Cl})\end{array}$ & $\begin{array}{l}\text { Proportion } \\
\text { adherent } \\
(95 \% \mathrm{Cl})\end{array}$ \\
\hline Apixaban & $77.15(75.03-79.27)$ & $0.62(0.53-0.72)$ & $81.75(74.32-89.18)$ & $0.74(0.62-0.87)$ \\
\hline Dabigatran & $73.94(68.94-78.93)$ & $0.55(0.48-0.61)$ & $75.04(67.74-82.34)$ & $0.65(0.54-0.76)$ \\
\hline Rivaroxaban & $78.30(72.47-84.14)$ & $0.64(0.54-0.73)$ & $77.45(68.9-85.96)$ & $0.73(0.64-0.81)$ \\
\hline Warfarin & No data available & $0.52(0.26-0.77)^{\star}$ & No data available & $0.50(0.32-0.68)^{*}$ \\
\hline All OACs & $76.62(73.91-79.33)$ & $0.63(0.58-0.68)$ & $73.72(68.36-79.08)$ & $0.70(0.65-0.76)$ \\
\hline \multicolumn{5}{|c|}{ Subanalysis: excluding studies with conflict of interest } \\
\hline Apixaban & $78.39(73.59-83.19)^{\star}$ & $0.51(0.49-0.53)^{*}$ & One study & $0.79(0.55-1.04)$ \\
\hline Dabigatran & $72.87(64.40-81.33)$ & $0.50(0.46-0.54) \dagger$ & $65.20(49.13-81.27)^{\star}$ & $0.67(0.50-0.84)$ \\
\hline Rivaroxaban & $74.25(69.84-78.66)^{\star}$ & $0.50(0.46-0.53)^{*}$ & $66.85(61.27-72.44)^{*}$ & $0.75(0.55-0.96)$ \\
\hline Warfarin & No data available & $0.39(0.38-0.39)$ & No data available & No data available \\
\hline All OACs & $73.40(69.86-76.94)$ & $0.56(0.49-0.62)$ & $65.56(59.41-71.72)$ & $0.68(0.58-0.79)$ \\
\hline \multicolumn{5}{|c|}{ Subanalysis: excluding studies with low and medium quality (assessed by ISPOR) } \\
\hline Apixaban & $77.15(75.03-79.27)^{\star}$ & $0.62(0.53-0.72)^{*}$ & $77.50(62.80-92.20)$ & $0.66(0.47-0.85)$ \\
\hline Dabigatran & $73.32(67.08-79.57)$ & $0.54(0.47-0.60)$ & $73.83(62.99-84.65)$ & $0.61(0.45-0.76)$ \\
\hline Rivaroxaban & $77.38(69.95-84.80)$ & $0.62(0.51-0.74)$ & $72.23(58.64-87.83)$ & $0.67(0.5-0.83)$ \\
\hline Warfarin & No data available & $0.52(0.26-0.77)^{*}$ & No data available & No data available \\
\hline All OACs & $77.29(74.19-80.40)$ & $0.63(0.58-0.68)$ & $68.61(62.63-74.58)$ & $0.67(0.58-0.76)$ \\
\hline \multicolumn{5}{|c|}{ Subanalysis: by adherence measure } \\
\hline \multicolumn{5}{|c|}{$M P R$} \\
\hline Apixaban & No data available & No data available & No data available & $0.75(0.64-0.87)$ \\
\hline Dabigatran & $77.00(69.16-81.84)^{\star}$ & $0.54(0.45-0.63)^{*}$ & No data available & $0.58(0.49-0.66)$ \\
\hline Rivaroxaban & No data available & No data available & No data available & $0.75(0.69-0.81)$ \\
\hline Warfarin & No data available & No data available & No data available & $0.59 \dagger$ \\
\hline All OACs & $81.01(77.21-84.81)$ & $0.57(0.51-0.63)$ & No data available & $0.74(0.64-0.83)$ \\
\hline \multicolumn{5}{|c|}{$P D C$} \\
\hline Apixaban & $77.15(75.03-79.27)$ & $0.62(0.53-0.72)$ & $80.67(69.40-91.94)$ & $0.74(0.45-1.02)$ \\
\hline Dabigatran & $72.41(65.90-78.91)$ & $0.55(0.47-0.63)$ & $74.05(65.56-82.53)$ & $0.67(0.52-0.82)$ \\
\hline Rivaroxaban & $76.38(71.35-81.40)$ & $0.64(0.54-0.74)$ & $75.74(67.44-84.03)$ & $0.69(0.57-0.82)$ \\
\hline Warfarin & No data available & $0.52(0.26-0.77)^{*}$ & No data available & $0.41 \dagger$ \\
\hline All OACs & $74.93(72.09-77.77)$ & $0.64(0.58-0.69)$ & $74.5(68.89-80.14)$ & $0.70(0.62-0.77)$ \\
\hline
\end{tabular}

*Pooled results of only two studies.

†Not pooled. Based on one study.

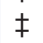

ISPOR, International Society of Pharmaco-economics and Outcomes Research; MPR, medication possession ratio; OAC, oral anticoagulant;

PDC, proportions days covered.

between apixaban and rivaroxaban over 6 months (OR:0.80, 95\% CI: 0.51-1.24) or 1 year (OR:1.02, 95\% CI: $0.79-1.33)$.

Studies reporting adherence among several cohorts with different characteristics

Three studies compared adherence between new versus experienced users. ${ }^{3750} 56$ McHorney et al reported greater mean PDC score for both rivaroxaban and apixaban (0.90 and 0.88 , respectively) among prior OAC users compared with naïve users $\left(0.87\right.$ and 0.86 , respectively) ${ }^{56}$ Borne $e t$ al reported a higher mean PDC score for apixaban users with prior warfarin experience compared with naïve users $(0.89 \pm 0.14$ vs naïe: $0.87 \pm 0.15, \quad \mathrm{p}<0.01) .{ }^{37}$ Confirming these results, Manzoor et al reported higher mean PDC for experienced users compared with naive users over 6 months $(83.3 \pm 24.6$ vs $72.3 \pm 31.3 ; \mathrm{p}<0.05), 9$ months $(81.2 \pm 26.4$ vs $67.3 \pm 33.8) ; \mathrm{p}<0.05)$ and 1 year $(79.9 \pm 27.6$ vs $63.7 \pm 35.2 ; \mathrm{p}<0.05) .^{50}$ 


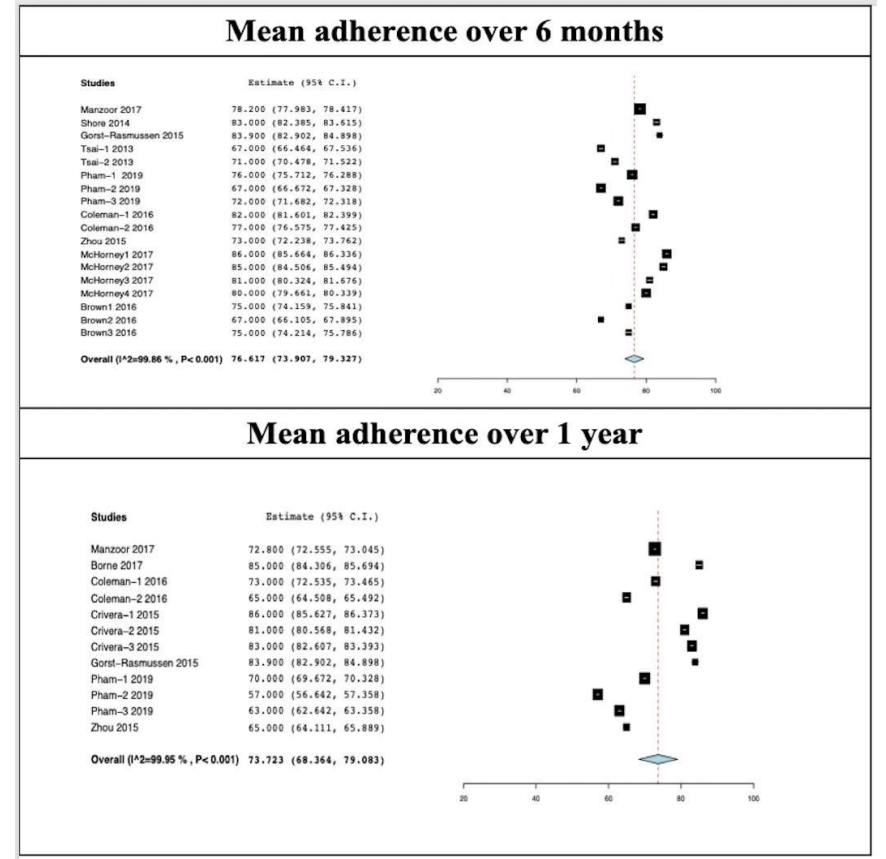

Figure 2 Forest plots illustrating patients' mean adherence scores over 6 months and 1 year post index date. See online supplementary file 4 for additional forest plots for each oral anticoagulant and subgroup analyses.

One study, Eapen et al, compared adherence among those prescribed OAC at discharge versus after discharge and reported that patients prescribed warfarin at discharge had significantly higher prescription fill rates compared with those prescribed after discharge at 3 months $(84.5 \%$ vs $12.3 \%$; $\mathrm{p}<0.001)$ and 1 year $(91.6 \%$ vs $16.8 \% ; \mathrm{p}<0.001) .{ }^{44}$

\section{Determinants of adherence}

Many factors were identified by the included studies as significant determinants of adherence. Summarising these under WHO's classification, the factors identified in the included studies to be significantly and positively associated with adherence were: Patient factors: history of hypertension, ${ }^{43} 49$ diabetes, ${ }^{37}$ stroke ${ }^{37}{ }^{52}$; Regimen factors: once daily dosing, ${ }^{3549}$ concomitant use of statin, ${ }^{43}{ }^{52} \mathrm{ACE}$ inhibitor or angiotensin II receptor blockers, ${ }^{43}{ }^{52}$ higher risk of bleeding ${ }^{43}$; and Social/economic factors: living in rural or deprived areas. ${ }^{52} 53$ Factors found to be significantly and negatively associated with adherence to OAC were: being a naïve OAC user, ${ }^{50}{ }^{56}$ twice daily dosing ${ }^{35} 49$ and impaired cognitive or functional ability. ${ }^{56}$ No healthcare system and condition factors related predictors of adherence were identified.

Conflicting results were reported for female sex, ${ }^{47} 4853$ age, ${ }^{374347-505253}$ risk of stroke, ${ }^{434753}$ presence of multiple comorbidities ${ }^{43} 505156$ and higher number of concomitant medications. ${ }^{50}{ }^{51}$ These factors were found to be predictors of high and low OAC adherence in different studies.

\section{Impacts of adherence}

Four studies assessed the clinical impact of adherence. ${ }^{35} 374259$ Alberts et al reported 50\% increased hazard of ischaemic stroke with DOAC non-adherence (aHR:1.50, 95\% CI:1.30-1.73) ${ }^{35}$ Deshpande et al reported non-adherent patients to be 1.82 times (aHR:1.82, 95\% CI: 1.24-2.67; $\mathrm{p}=0.002$ ) and 2.08 times (aHR:2.08, 95\% CI: 1.11-3.89; $\mathrm{p}=0.02)$ more likely to experience an ischaemic stroke compared with adherent patients, over 6 and 12 months, respectively. ${ }^{42}$ Similarly, Borne et al reported a higher risk of death or stroke per 0.1 drop in the PDC among dabigatran users (HR:1.07, 95\% CI: $1.03-1.12 ; \mathrm{p}<0.01) .{ }^{37}$ Shore $e t$ al reported a $13 \%$ increase in risk of combined all-cause mortality and stroke with

Table 4 Pooled adherence results from studies reporting adherence to more than one drug in the same cohort

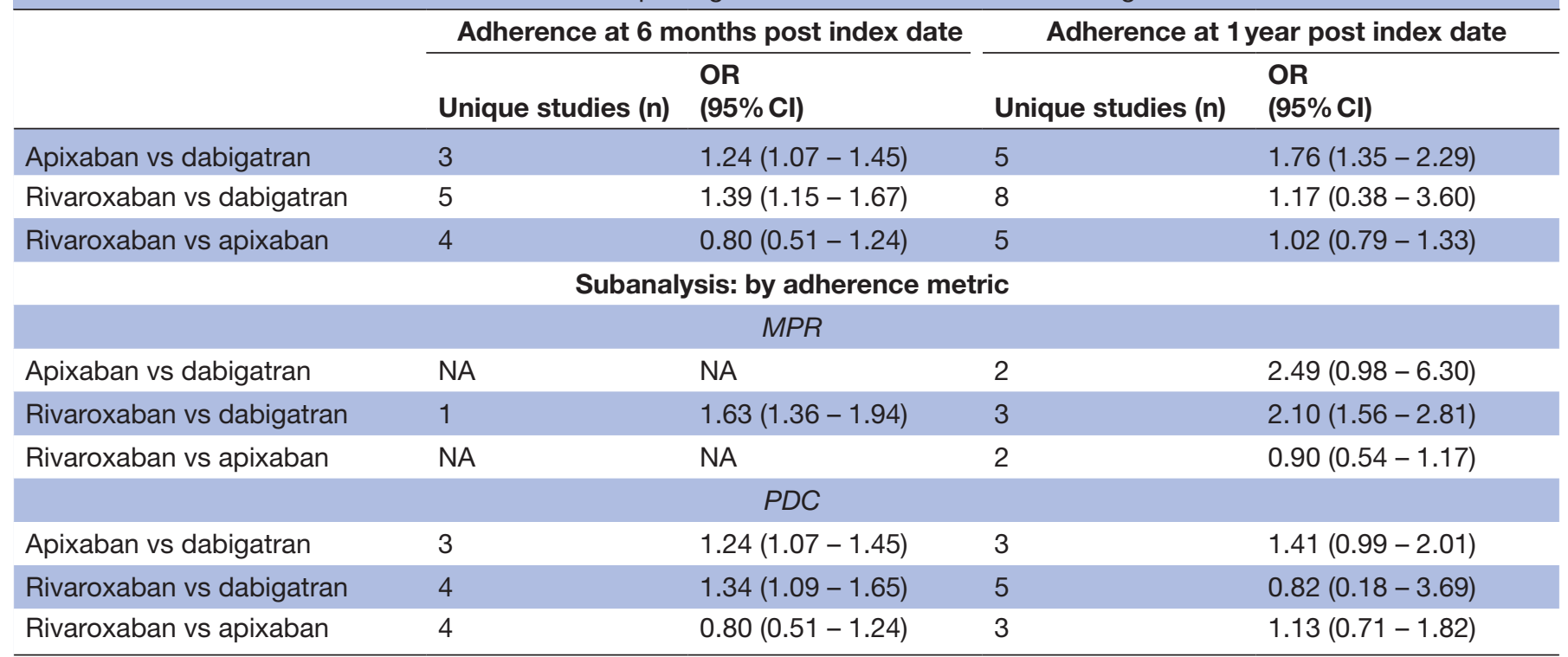

MPR, medication possession ratio; PDC, proportions days covered. 
lower adherence (aHR:1.13, 95\% CI: $1.07-1.19$ per $10 \%$ decrease in PDC) but found no association between adherence and non-fatal bleeding events (aHR:1.04 per $10 \%$ increase in PDC, 95\% CI: 0.94-1.14) or myocardial infarction (aHR:0.97 per 10\% increase in PDC, 95\% CI: $0.78-1.21) .^{59}$

Two studies measured the economic impacts of adherence. ${ }^{38} 43$ Casciano et al reported significantly more inpatient and emergency room encounters and longer length of stay for non-adherent patients compared to adherent patients and Deshpande et al reported significantly higher annual adjusted per-patient medical cost (inpatient and outpatient) for non-adherent users compared with adherent ones (US\$30 485 vs $\$ 23544 ; \mathrm{p} \leq 0.001$ ). ${ }^{38} 43$

\section{DISCUSSION}

In this systematic review, we synthesised observational data of over half a million patients with AF to reveal that up to $30 \%$ are non-adherent to OACs, and that non-adherent patients are more likely to experience stroke, death and incur higher medical costs compared with adherent patients. We also found that older age, higher stroke risk, once-daily regimen, history of hypertension, diabetes or stroke, concomitant cardiovascular medications, living in rural areas and being an experienced OAC user could be associated with better adherence.

Adherence to OACs among patients with AF has been thoroughly studied in developed countries. In our study, pooled proportion of adherent patients at 6 months and 1 year were $63 \%$ and $70 \%$, respectively, which are higher than those found for other chronic cardiovascular medications such as statins (54\%) and antihypertensives $(59 \%) .{ }^{65}$ However, our finding that up to $37 \%$ of patients with AF do not adhere to OACs is concerning considering the detrimental consequences of non-adherence in this particular clinical context. We were unable to ascertain whether the conveniences of DOACs translates into better adherence compared with warfarin due to lack of adherence data on warfarin, a likely result of warfarin dose variations complicating $\mathrm{MPR}$ and $\mathrm{PDC}$ ascertainment from administrative data. Between DOACs, however, adherence was found to be similar, although dabigatran appeared to have slightly lower adherence than apixaban and rivaroxaban.

Many patient-related-related, regimen-related and social/economic-related factors were identified by the included studies as significant determinants of adherence. It should be noted that each of these factors were reported to have a significant impact on adherence by one or two studies. The limited number of prospective observational studies on the topic restricted our ability to identify important psychosocial determinants as administrative data fall short in recording patients' knowledge gaps, misconceptions and varying values and preferences, all of which have frequently been reported in patients with $A F{ }^{66-71}$ Further, questions remain about the role of sex, age, risk of stroke, presence of multiple comorbidities and number of concomitant medications on adherence. One explanation for the inconsistencies we observed could be differences in how these factors were defined in our included studies. A 2019 systematic review of 34 systematic reviews on determinants of adherence to cardiovascular medications (beta blockers, calcium channel blockers, ACE inhibitors, angiotensin II receptor blockers and diuretics) also reported inconsistent results for the role of gender in adherence. ${ }^{72}$ These authors also found that the effects of concomitant medications and comorbidities seem to be drug-specific and condition-specific, which could explain some of the interstudy variability with this factor. ${ }^{72}$ A multivariate patientlevel meta-regression analysis could provide more clarity to these issues with OACs in patients with AF. Nevertheless, our findings indicate potential opportunities for interventions such as education and counselling for younger or newly diagnosed patients (naïve users) and adherence support for those on twice daily dosed OACs.

Lastly, we looked at outcomes of poor adherence. Our review found evidence of association between lower adherence and strokes, mortality, healthcare utilisation and costs. Our findings confirm the results of a 2017 systematic review of 79 studies across 14 disease groups which reported that $\$ 3347-\$ 19472$ are attributed to non-adherence per patient per year among those with cardiovascular conditions (hypertension, hypercholesterolaemia and chronic heart failure). ${ }^{73}$ Our findings in relation to clinical outcomes are in line with results of meta-analyses of a large body of research showing that poor adherence across a range of conditions was associated with a $26 \%$ increased risk of poor treatment outcomes. $^{74}$ The adherence-outcome relationship is, however, very complex, and dependant on many factors, including the nature of the disease. ${ }^{74}$ This is why it was important to summarise the strength of this relationship specifically in AF. Our findings, while based on only four studies, reveal the relationship between lower adherence and poor clinical outcomes in patients with $\mathrm{AF}$, and support the potential of interventions aimed at increasing adherence in patients with $\mathrm{AF}^{73-79}$

\section{Limitations}

This review was primarily limited by gaps in the available evidence. Given our interest in observational data, our evidence was narrowed to developed countries where the technology and infrastructure for systematic collection of such data is available. The high number of studies from a few developed countries introduced the possibility of duplicate patients in the analysis since many of the included studies used the same database with overlapping periods. ${ }^{35}$ 38-40 5064 Furthermore, there may be potential for publication bias or under-representation from studies from developing countries. As described in the Methods section, we attempted to assess publication bias using funnel plots but were limited with few studies reporting measures of association. Nonetheless, for these 
meta-analyses, findings do not suggest presence of publication bias (online supplementary file 3 ).

Another limitation of our analysis was the high heterogeneity $\left(\mathrm{I}^{2}>80 \%\right)$ among the studies. Possible sources of heterogeneity include differences in patient inclusion criteria (eg, OAC naïve vs experienced); methods for handling and defining medication switches, stockpiling, refill gaps and hospitalisation dates; fixed versus variable observational periods and adherence measure used (PDC vs MPR). Subgroup analyses did not affect the amount of statistical heterogeneity detected. Nonetheless, in addition to the summary measures derived from metaanalysis, we were able to detect the range of adherence measures from the included studies. Finally, drug utilisation consists of initiation, implementation and discontinuation, ${ }^{1580}$ and the focus of this study was confined to the implementation phase. Systematic reviews of OAC initiation and discontinuation are needed to provide a complete picture of medication taking behaviour in patients with $\mathrm{AF}$.

\section{FUTURE DIRECTIONS}

Our understanding of the comparative adherence between warfarin and DOACs among patients with $\mathrm{AF}$ is currently impeded by lack of observational data on warfarin. Sophisticated statistical models are needed to calculate days' supply of warfarin, despite its varying dose, to allow measurement of MPR or PDC for this drug using administrative data. Furthermore, we lack information on patterns of non-adherence to OACs. All of the current studies have treated adherence as a static behaviour, calculating and reporting it using a single summary measure. This methodological approach does not provide a complete picture of adherence, which is a dynamic behaviour that changes over time. ${ }^{25} 81$ Characterisation of adherence patterns over time is vital in understanding the problem of poor adherence and targeting the right patients at the right time with the right interventions. ${ }^{82-86}$

There is a need for more research investigating the clinical and economic consequences of poor adherence as the current evidence is limited to findings of four studies. Moreover, a clinically meaningful OAC adherence threshold has yet to be determined in $\mathrm{AF}^{35} 374259$ While the association between taking more than $80 \%$ of medications and improved clinical outcomes has been shown in four AF studies, it remains unclear if this is the optimal threshold for AF. ${ }^{35} 374259$ Clinically relevant adherence cut-off values have been shown to differ widely (from $58 \%$ to $85 \%$ ) in different diseases, and even among drug classes. ${ }^{1487}$ As with antiretroviral medications, given the detrimental consequences of OAC non-adherence, the clinically meaningful threshold for 'good adherence' to OACs may need to be much higher than $80 \%{ }^{87}$

\section{CONCLUSION}

Synthesis of observational data suggests that overall OAC adherence in patients with $\mathrm{AF}$ is below the conventional threshold of 'adherent' (80\%). These findings, combined with evidence that lower adherence is associated with poor clinical outcomes and higher costs, suggest an important therapeutic challenge in this patient population. Our study also highlights the need for more consistent measures of adherence, and more research to characterise patterns of OAC non-adherence, identifying determinants of poor OAC adherence and investigate the clinical and economic consequences of $\mathrm{OAC}$ non-adherence.

\section{Twitter Mary A De Vera @maryadevera}

Contributors Conceived the study: SS, PSL, MADV; Designed the search strategy: SS, MADV, PSL; Conducted the literature search: SS; Screened titles and abstracts: SS, RT; Screened full texts: SS, RT; Extracted data: SS, RT; Made methodological decisions (data synthesis and analysis): MADV, SS; Analysed the data: SS; Conducted quality assessment; SS, RT; Interpreted the results: SS, PSL, JA, MADV; Prepared the manuscript first draft: SS, MDV, PSL, RT; Reviewed the manuscript and provided critical feedback: JA, MADV, PSL; Revised the manuscript: SS, PSL, RT, MADV.

Funding PSL's research is partially supported by the UBC David H MacDonald Professorship in Clinical Pharmacy. MADV holds a Canada Research Chair in Medication Adherence, Utilisation and Outcomes and is a Michael Smith Foundation for Health Research Scholar.

Competing interests None declared.

Patient and public involvement Patients and/or the public were not involved in the design, or conduct, or reporting, or dissemination plans of this research.

Patient consent for publication Not required.

Ethics approval Ethical approval for this study was not required per our institution's policies.

Provenance and peer review Not commissioned; externally peer reviewed. Data availability statement № data are available. No data are available.

Open access This is an open access article distributed in accordance with the Creative Commons Attribution Non Commercial (CC BY-NC 4.0) license, which permits others to distribute, remix, adapt, build upon this work non-commercially, and license their derivative works on different terms, provided the original work is properly cited, appropriate credit is given, any changes made indicated, and the use is non-commercial. See: http://creativecommons.org/licenses/by-nc/4.0/.

ORCID iD

Shahrzad Salmasi http://orcid.org/0000-0003-1330-3388

\section{REFERENCES}

1 Morillo CA, Banerjee A, Perel P, et al. Atrial fibrillation: the current epidemic. J Geriatr Cardiol 2017;14:195-203.

2 Wolf PA, Abbott RD, Kannel WB. Atrial fibrillation as an independent risk factor for stroke: the Framingham study. Stroke 1991;22:983-8.

3 Hart RG, Pearce LA, McBride R, et al. Factors associated with ischemic stroke during aspirin therapy in atrial fibrillation: analysis of 2012 participants in the SPAF I-III clinical trials. The stroke prevention in atrial fibrillation (SPAF) Investigators. Stroke 1999;30:1223-9.

4 World Health Organization. The top 10 causes of death 2018. Available: https://www.who.int/news-room/fact-sheets/detail/thetop-10-causes-of-death [Accessed 2 May 2019].

5 Wolf PA, Dawber TR, Thomas HE, et al. Epidemiologic assessment of chronic atrial fibrillation and risk of stroke: the Framingham study. Neurology 1978;28:973-7.

6 Marini C, De Santis F, Sacco S, et al. Contribution of atrial fibrillation to incidence and outcome of ischemic stroke: results from a population-based study. Stroke 2005;36:1115-9.

7 McGrath ER, Kapral MK, Fang J, et al. Association of atrial fibrillation with mortality and disability after ischemic stroke. Neurology 2013;81:825-32. 
8 Fang MC, Go AS, Chang Y, et al. Long-Term survival after ischemic stroke in patients with atrial fibrillation. Neurology 2014;82:1033-7.

9 Connolly SJ, Ezekowitz MD, Yusuf S, et al. Dabigatran versus warfarin in patients with atrial fibrillation. $N$ Engl J Med 2009;361:1139-51.

10 Giugliano RP, Ruff CT, Braunwald E, et al. Edoxaban versus warfarin in patients with atrial fibrillation. N Engl J Med 2013;369:2093-104.

11 Hart RG, Pearce LA, Aguilar MI. Meta-Analysis: antithrombotic therapy to prevent stroke in patients who have nonvalvular atrial fibrillation. Ann Intern Med 2007;146:857-67.

12 Patel MR, Mahaffey KW, Garg J, et al. Rivaroxaban versus warfarin in nonvalvular atrial fibrillation. N Engl J Med 2011;365:883-91.

13 Kirchhof P, Benussi S, Kotecha D, et al. 2016 ESC guidelines for the management of atrial fibrillation developed in collaboration with EACTS. Eur J Cardiothorac Surg 2016;50:e1-88.

14 Karve S, Cleves MA, Helm M, et al. Good and poor adherence: optimal cut-point for adherence measures using administrative claims data. Curr Med Res Opin 2009;25:2303-10.

15 De Geest S, Zullig LL, Dunbar-Jacob J, et al. ESPACOMP medication adherence reporting guideline (emerge). Ann Intern Med 2018;169:30-5

16 Aronis KN, Hylek EM. Evidence gaps in the era of non-vitamin K oral anticoagulants. J Am Heart Assoc 2018;7:e007338.

17 Chin PK, Doogue MP. Long-Term prescribing of new oral anticoagulants. Aust Prescr 2016;39:200-4.

18 Mekaj YH, Mekaj AY, Duci SB, et al. New oral anticoagulants: their advantages and disadvantages compared with vitamin $\mathrm{K}$ antagonists in the prevention and treatment of patients with thromboembolic events. Ther Clin Risk Manag 2015;11:967-77.

19 Obamiro KO, Chalmers L, Bereznicki LRE. A summary of the literature evaluating adherence and persistence with oral anticoagulants in atrial fibrillation. Am J Cardiovasc Drugs 2016;16:349-63.

20 Chatterjee S, Sardar P, Giri JS, et al. Treatment discontinuations with new oral agents for long-term anticoagulation: insights from a metaanalysis of 18 randomized trials including 101,801 patients. Mayo Clin Proc 2014;89:896-907.

21 Shehab A, Bhagavathula AS, Abebe TB, et al. Patient adherence to novel oral anticoagulants (NOACs) for the treatment of atrial fibrillation and occurrence of associated bleeding events: a systematic review and meta-analysis. Curr Vasc Pharmacol 2019;17:341-9.

22 Liberati A, Altman DG, Tetzlaff J, et al. The PRISMA statement for reporting systematic reviews and meta-analyses of studies that evaluate health care interventions: explanation and elaboration. PLoS Med 2009;6:e1000100.

23 Stroup DF, Berlin JA, Morton SC, et al. Meta-Analysis of observational studies in epidemiology: a proposal for reporting. meta-analysis of observational studies in epidemiology (moose) group. JAMA 2000;283:2008-12.

24 Osterberg L, Blaschke T. Adherence to medication. N Engl J Med 2005;353:487-97.

25 Andrade SE, Kahler KH, Frech F, et al. Methods for evaluation of medication adherence and persistence using automated databases. Pharmacoepidemiol Drug Saf 2006;15:565-74.

26 Baumgartner PC, Haynes RB, Hersberger KE, et al. A systematic review of medication adherence thresholds dependent of clinical outcomes. Front Pharmacol 2018;9:1290.

27 World Health Organisation. Adherence to long-term therapies: evidence to action. towards the solution: five interacting dimensions affect adherence. Switzerland, 2003.

28 Higgins JPT, Thompson SG, Deeks JJ, et al. Measuring inconsistency in meta-analyses. BMJ 2003;327:557-60.

29 Willis $\mathrm{BH}$, Riley RD. Measuring the statistical validity of summary meta-analysis and meta-regression results for use in clinical practice. Stat Med 2017;36:3283-301.

30 Wallace BC, Dahabreh IJ, Trikalinos TA, et al. Closing the Gap between Methodologists and End-Users: $R$ as a Computationa Back-End. J Stat Softw 2012;49:15

31 Peters JL, Sutton AJ, Jones DR, et al. Comparison of two methods to detect publication bias in meta-analysis. JAMA 2006;295:676-80.

32 Peterson AM, Nau DP, Cramer JA, et al. A checklist for medication compliance and persistence studies using retrospective databases. Value Health 2007;10:3-12.

33 von Elm E, Altman DG, Egger M, et al. The strengthening the reporting of observational studies in epidemiology (STROBE) statement: guidelines for reporting observational studies. Int $J$ Surg 2014:12:1495-9.

34 Cochrane community. Editorial and publishing policy resource conflicts of interest and Cochrane reviews, 2014. Available: https:// community.cochrane.org/editorial-and-publishing-policy-resource/ ethical-considerations/conflicts-interest-and-cochrane-reviews [Accessed 10 July 2019].

35 Alberts MJ, Peacock WF, Fields LE, et al. Association between onceand twice-daily direct oral anticoagulant adherence in nonvalvular atrial fibrillation patients and rates of ischemic stroke. Int J Cardiol 2016;215:11-13.

36 Beyer-Westendorf J, Ehlken B, Evers T. Real-World persistence and adherence to oral anticoagulation for stroke risk reduction in patients with atrial fibrillation. Europace 2016;18:1150-7.

37 Borne RT, O'Donnell C, Turakhia MP, et al. Adherence and outcomes to direct oral anticoagulants among patients with atrial fibrillation: findings from the Veterans health administration. BMC Cardiovasc Disord 2017;17:236.

38 Casciano JP, Dotiwala ZJ, Martin BC, et al. The costs of warfarin underuse and nonadherence in patients with atrial fibrillation: a commercial insurer perspective. J Manag Care Pharm 2013;19:302-16.

39 Coleman C, Yuan Z, Schein J, et al. Importance of balancing follow-up time and impact of oral-anticoagulant users' selection when evaluating medication adherence in atrial fibrillation patients treated with rivaroxaban and apixaban. Curr Med Res Opin 2017;33:1033-43.

40 Coleman Cl, Tangirala M, Evers T. Medication adherence to rivaroxaban and dabigatran for stroke prevention in patients with non-valvular atrial fibrillation in the United States. Int J Cardio 2016;212:171-3.

41 Crivera C, Nelson WW, Bookhart B, et al. Pharmacy quality alliance measure: adherence to non-warfarin oral anticoagulant medications. Curr Med Res Opin 2015;31:1889-95.

42 Deshpande CG, Kogut S, Laforge R, et al. Impact of medication adherence on risk of ischemic stroke, major bleeding and deep vein thrombosis in atrial fibrillation patients using novel oral anticoagulants. Curr Med Res Opin 2018;34:1285-92.

43 Deshpande CG, Kogut S, Willey C. Real-World health care costs based on medication adherence and risk of stroke and bleeding in patients treated with novel anticoagulant therapy. J Manag Care Spec Pharm 2018;24:430-9.

44 Eapen ZJ, Mi X, Qualls LG, et al. Adherence and persistence in the use of warfarin after hospital discharge among patients with heart failure and atrial fibrillation. J Card Fail 2014;20:23-30.

45 Forslund T, Wettermark B, Hjemdahl P. Comparison of treatment persistence with different oral anticoagulants in patients with atrial fibrillation. Eur J Clin Pharmacol 2016;72:329-38.

46 Gomez-Lumbreras A, Cortes J, Giner-Soriano M, et al. Characteristics of apixaban-treated patients, evaluation of the dose prescribed, and the persistence of treatment: a cohort study in Catalonia. J Cardiovasc Pharmacol Ther 2018;23:494-501.

47 Gorst-Rasmussen A, Skjøth F, Larsen TB, et al. Dabigatran adherence in atrial fibrillation patients during the first year after diagnosis: a nationwide cohort study. J Thromb Haemost 2015;13:495-504.

48 Harper P, Pollock D, Stephens M. Dabigatran persistence and adherence in New Zealand: a nationwide retrospective observational study. BMJ Open 2018;8:e020212.

49 Jacobs MS, Schouten JF, de Boer PT, et al. Secondary adherence to non-vitamin-K antagonist oral anticoagulants in patients with atrial fibrillation in Sweden and the Netherlands. Curr Med Res Opin 2018;34:1839-47.

50 Manzoor BS, Lee TA, Sharp LK, et al. Real-World adherence and persistence with direct oral anticoagulants in adults with atrial fibrillation. Pharmacotherapy 2017;37:1221-30.

51 Márquez-Contreras E, Martell-Carlos N, Gil-Guillén V, et al. Therapeutic compliance with rivaroxaban in preventing stroke in patients with non-valvular atrial fibrillation: CUMRIVAFA study. Curr Med Res Opin 2016;32:2013-20.

52 Maura G, Pariente A, Alla F, et al. Adherence with direct oral anticoagulants in nonvalvular atrial fibrillation new users and associated factors: a French nationwide cohort study. Pharmacoepidemiol Drug Saf 2017;26:1367-77.

53 McAlister FA, Wiebe N, Hemmelgarn BR. Time in therapeutic range and stability over time for warfarin users in clinical practice: a retrospective cohort study using linked routinely collected health data in Alberta, Canada. BMJ Open 2018;8:e016980.

54 McCormick D, Gurwitz JH, Goldberg RJ, et al. Prevalence and quality of warfarin use for patients with atrial fibrillation in the long-term care setting. Arch Intern Med 2001;161:2458-63.

55 McHorney CA, Ashton V, Laliberté F, et al. Adherence to rivaroxaban compared with other oral anticoagulant agents among patients with nonvalvular atrial fibrillation. J Manag Care Spec Pharm 2017;23:980-8. 
56 McHorney CA, Crivera C, Laliberté F, et al. Adherence to rivaroxaban versus apixaban among patients with non-valvular atrial fibrillation: analysis of overall population and subgroups of prior oral anticoagulant users. PLoS One 2018;13:e0194099.

57 Mueller T, Alvarez-Madrazo S, Robertson C, et al. Use of direct oral anticoagulants in patients with atrial fibrillation in Scotland: applying a coherent framework to drug utilisation studies. Pharmacoepidemiol Drug Saf 2017;26:1378-86.

58 Pham PN, Brown JD. Real-world adherence for direct ora anticoagulants in a newly diagnosed atrial fibrillation cohort: does the dosing interval matter? BMC Cardiovasc Disord 2019;19:64.

59 Shore S, Carey EP, Turakhia MP, et al. Adherence to dabigatran therapy and longitudinal patient outcomes: insights from the Veterans health administration. Am Heart J 2014;167:810-7.

60 Sørensen R, Jamie Nielsen B, Langtved Pallisgaard J, et al. Adherence with oral anticoagulation in non-valvular atrial fibrillation: a comparison of vitamin $\mathrm{K}$ antagonists and nonvitamin K antagonists. Eur Heart J Cardiovasc Pharmacother 2017;3:151-6.

61 Tsai K, Erickson SC, Yang J, et al. Adherence, persistence, and switching patterns of dabigatran etexilate. Am J Manag Care 2013;19:e325-32.

62 Yao X, Abraham NS, Alexander GC, et al. Effect of adherence to oral anticoagulants on risk of stroke and major bleeding among patients with atrial fibrillation. J Am Heart Assoc 2016;5.

63 Zhou M, Chang H-Y, Segal JB, et al. Adherence to a novel oral anticoagulant among patients with atrial fibrillation. J Manag Care Spec Pharm 2015;21:1054-62.

64 Brown JD, Shewale AR, Talbert JC. Adherence to rivaroxaban, dabigatran, and apixaban for stroke prevention in incident, treatment-naïve nonvalvular atrial fibrillation. J Manag Care Spec Pharm 2016;22:1319-29.

65 Chowdhury R, Khan H, Heydon E, et al. Adherence to cardiovascular therapy: a meta-analysis of prevalence and clinical consequences. Eur Heart J 2013;34:2940-8.

66 Salmasi S, De Vera MA, Barry A, et al. Assessment of condition and medication knowledge gaps among atrial fibrillation patients: a systematic review and meta-analysis. Ann Pharmacother 2019;53:1060028019835845:773-85. 0(0).

67 Salmasi S, Kwan L, MacGillivray J, et al. Assessment of atrial fibrillation patients' education needs from patient and clinician perspectives: a qualitative descriptive study. Thromb Res 2019;173:109-16.

68 Lee VWY, Tam CS, Yan BP, et al. Barriers to warfarin use for stroke prevention in patients with atrial fibrillation in Hong Kong. Clin Cardiol 2013;36:166-71.

69 McCabe PJ, Barnason SA, Houfek J. Illness beliefs in patients with recurrent symptomatic atrial fibrillation. Pacing Clin Electrophysiol 2011;34:810-20.

70 McCabe PJ, Rhudy LM, DeVon HA. Patients' experiences from symptom onset to initial treatment for atrial fibrillation. J Clin Nurs 2015;24:786-96.
71 Loewen PS, Ji AT, Kapanen A, et al. Patient values and preferences for antithrombotic therapy in atrial fibrillation. A narrative systematic review. Thromb Haemost 2017;117:1007-1022.

72 Leslie KH, McCowan C, Pell JP. Adherence to cardiovascular medication: a review of systematic reviews. J Public Health 2019;41:e84-94.

73 Cutler RL, Fernandez-Llimos F, Frommer M, et al. Economic impact of medication non-adherence by disease groups: a systematic review. BMJ Open 2018;8:e016982.

74 DiMatteo MR, Giordani PJ, Lepper HS, et al. Patient adherence and medical treatment outcomes: a meta-analysis. Med Care 2002;40:794-811.

75 Bramley TJ, Gerbino PP, Nightengale BS, et al. Relationship of blood pressure control to adherence with antihypertensive monotherapy in 13 managed care organizations. J Manag Care Pharm 2006;12:239-45

76 Ho PM, Rumsfeld JS, Masoudi FA, et al. Effect of medication nonadherence on hospitalization and mortality among patients with diabetes mellitus. Arch Intern Med 2006;166:1836-41.

77 Kennedy-Martin T, Boye KS, Peng X. Cost of medication adherence and persistence in type 2 diabetes mellitus: a literature review. Patient Prefer Adherence 2017;11:1103-17.

78 Rasmussen JN, Chong A, Alter DA. Relationship between adherence to evidence-based pharmacotherapy and long-term mortality after acute myocardial infarction. JAMA 2007;297:177-86.

79 Tangkiatkumjai M, Walker D-M, Praditpornsilpa K, et al. Association between medication adherence and clinical outcomes in patients with chronic kidney disease: a prospective cohort study. Clin Exp Nephrol 2017;21:504-12.

80 Vrijens B, De Geest S, Hughes DA, et al. A new taxonomy for describing and defining adherence to medications. Br J Clin Pharmacol 2012;73:691-705.

81 Gellad WF, Thorpe CT, Steiner JF, et al. The myths of medication adherence. Pharmacoepidemiol Drug Saf 2017;26:1437-41.

82 Franklin JM, Krumme AA, Tong AY, et al. Association between trajectories of statin adherence and subsequent cardiovascular events. Pharmacoepidemiol Drug Saf 2015;24:1105-13.

83 Franklin JM, Shrank WH, Pakes J, et al. Group-Based trajectory models: a new approach to classifying and predicting long-term medication adherence. Med Care 2013;51:789-96.

84 Lo-Ciganic W-H, Donohue JM, Jones BL, et al. Trajectories of diabetes medication adherence and hospitalization risk: a retrospective cohort study in a large state Medicaid program. J Gen Intern Med 2016;31:1052-60.

85 Lo-Ciganic W-H, Gellad WF, Gordon AJ, et al. Association between trajectories of buprenorphine treatment and emergency department and in-patient utilization. Addiction 2016;111:892-902.

86 Modi AC, Rausch JR, Glauser TA. Patterns of nonadherence to antiepileptic drug therapy in children with newly diagnosed epilepsy. JAMA 2011;305:1669-76.

87 Viswanathan S, Justice AC, Alexander GC, et al. Adherence and HIV RNA suppression in the current era of highly active antiretroviral therapy. J Acquir Immune Defic Syndr 2015;69:493-8. 